\title{
The Direction of Corporate Governance and Challenges--Lessons and Learning
}

\author{
Yuanzhuo $\mathrm{Wu}$ \\ College of Public Administration \\ Nanchang university, \\ Nanchang, China \\ yuanzhuo.wu@gmail.com
}

\author{
Chun Fu \\ The Research Center of Central China Economic \\ Development, Nanchang university, \\ Nanchang, China \\ ccfu@ncu.edu.cn
}

\begin{abstract}
The key drivers of the future direction of corporate governance principles, policies and practices have been discussed. The challenges involved in producing improved systems of governance have been evaluated. From literature reviewing, lessons and learning from case studies in companies have been explained, excepting governance systems, corporate culture, business ethic is important to the good governance.
\end{abstract}

Keywords-corporate governance; governance systems; Corporate culture; business ethnic

\section{CORPORATE GOVERNANCE AND THE PRINCIPLES}

Corporate governance is about using the way such as processes, customs, policies, laws, and institutions to govern corporate entities[1]. Nowadays companies have increasingly discovered that traditional financial method is not sufficient to attract investors and what they need to do is to "demonstrate conduct consistent with the principles of good corporate governance."[2] The corporate governance codes of good practice has a close affinity with each other all over the world, because they learn from one another and gain experience through competition. Though their ways vary somewhat in detail, "all emphasizes corporate transparency, accountability, reporting, and the independence of the governing body from management, and many now include strategic risk assessment and corporate social responsibility.

" [3] In these companies, Corporate Governance is on the approach of convergence.

While not all the codes looked same, as the result of development stage, stage involvement, financial system (ownership patterns, financing, legal system, market for corporate control)[13], and cultural influence, the models of corporate governance changes from one place to another. When some countries have a sound corporate governance, some places are busy with their problems. But what needed to get attention is none of the models is the perfect one.

\section{SituATION AND CHALLENGE OF CHINESE AND AMERICAN COOPERATE GOVERNANCE}

US-Based Model can be a good example. The US model is also named as "the unitary system, ""which based on the system of individual or institutional shareholders that are outsiders of the corporation."[4] The management and the board of directors are the other sides of the corporate governance triangle. The aim of this model is to separate the control and ownership. As a consequence, almost every company has the unitary board with independent outside directors. All of the directors are elected by shareholders. In this case the shareholders benefit can be protected. Unlike uk-commonwealth based Model, CEO can also be the chairman. It is another reason why many companies include more outside directors now.[4] The company law based on common law and the case law can be a supplement. US accounting and governance are rule based, regulator always asks it is legal or not. Ten years ago, the US Model was famous for its trustworthy corporate regulation and reporting practices, while the case of ENRON broke the confident of investors. In 2002, Sarbans-Oxley Act was issued to change this situation, the corporate managers have to work hard for shareholders to do their optimum use[5]. And it as respect helped restore trust in markets and improved investor confidence by using the way "increasing accountability, speeding up the reporting, and making more independent audits"[6].That besides why the corporate scandals can be considered as a key driver of change in governance systems: The Government and the corporation have learned bitter lessons in this respect, carried the pressure and query from the pubic. To recover losses and wall up the danger happened once more. They need to figure out the correspondent countermeasures. However, the US-Based Model is not invincible since it was covered from ENRON, the global economic crisis destroyed the thought that corporate governance system all over the world would converge on us-based.

But the economic crisis gives opportunity to "super-economies" such as India and China.Take China as an example, due to the high GDP in the following years, China escaped the big impact and has learned a good lesson written in blood. Chinese Model, which government traditionally plays a strong role in the governance system, led and managed by the Chinese Communist Party, has to deal with the problem such as accounting manipulation, interest conflicts, overinvestment, excessive CEO pay in a long time. It uses a two-tier model, but it relaxes inner control, and is lacking in supervision[13]. The benefit of minority shareholders is frequently damaged. Although the situation is going against China, China is still keeping optimistic, a series of reforms are taking place and the effective. If the model is in Good scenario, China will have effective monitoring and have an improvement in 
transparency[7]. However, no matter Chinese model in what situation, because China is the biggest developing country with a high increasing speed of economic growth, and it is the important trading partners of many countries, its Corporate Governance will influence each other deeply. So is the Indian. Therefore, the "super-economies" could be a key driver of change in governance systems.

\section{TREND AND KEY FACTORS OF COOPERATE GOVERNANCE}

There are so many other key drivers of change in governance systems. The most important one may be the effects of globalization. Companies that are "truly global in strategic outlook, with world-wide production, service provision, added-value chain, markets and customers, which call on international sources of finance"[3]. Their global investors are all over the world, help them doing common governance practices. It is also connected with other drivers, such as cross-border "mega-mergers" and trans-national board membership. The corporation needs to narrow the gap between itself and other companies, and then becomes integrated into the global market. Globalization strengthens the ties between countries in the business area. This leads to the development of the multinational corporation, and then the cross-border "mega-mergers" is nothing new now. For instance, Chinese carmaker Geely completes acquisition of Volvo From Ford in 2010, Lenovo completes purchase of IBM's PC Unit in 2005.Merger can be an opportunity, but it is also a challenge.Merger not only can bring benefits like synergy, Strong market power, efficiency, SCP debate, the change of Merger policy, complementary capabilities, and reduces the risk, but also bring problems like Hubris, overpayment, too expensive Merger Costs, the change of merger mechanics, and corporate culture clashes[13].In order not to be hostile takeover, and find a way to purchasing other companies to gain own strength, the Corporate Governance in some firms has to change, especially the firms in developing countries, such as China. Some evidence shows that many Chinese companies made a hasty decision. They were taken over, lost their benefit, and soon forgotten by their acquirers. And on the other hand, as Tricker said in 2011, cross-border mergers of stock markets could similarly influence country-centric investment dealing and corporate governance expectations. At the same time promoting global securities trading could develop electronic trading in stocks.

Corporate culture clashes are because different board structures and governance practices have been formed by the reasons like history, culture and ethnic groupings. Japan uses keiretsu, continental European countries use the two-tier board structures model, overseas Chinese use the family domination."Views differ on ownership rights and the basis of shareholder power." [3] The structure of corporate boards is under the crash. It is another driver. Currently the structure needs to be redesigned. The underlying idea of the corporation should be considered over, and the urgent task at hand is built a pluralistic foundation to fit the corporate groups and strategic alliance networks[3] .

Although the reform of corporate governance practices around the world is a historical trend, there are still great challenges involved in producing improved systems of governance, such as the differentiation between countries, financial markets, existing practices, the attitude towards reform, "the nature of a particular sector"[8].

On the other hand, the Standard of Law changes from countries. For example, a company which understands the law of its own country would make a better use of it than such companies which come from abroad. The outcome of corporate governance is influenced. And not all of the countries authorize international standard, the judicial system of them is still weak. The undeveloped legal system and the unfair law may lead to an unsatisfied and unjust result of a business case.

A shaky worldwide financial market can be another challenge. On the other hand, the fiscal crisis is a key driver of change in governance systems. The fiscal crisis in 2008, let public found out the failure of oversight can ruin companies. The supervisory boards tend to be "decorate." They"do not believe they are getting enough of the right kinds of information in order for them to effectively execute their responsibility of risk oversight"[9]. Risk assessment and management are the first thing the Corporate Governance needs to fix on. Assessing managements ability to evade risk must be paid sufficient attention. Roles between boards and management should be redefined. An increased demand for transparency and more practical Operating Model is even emphasized. The challenge is, government decided to limit and control compensation of senior management and involved in corporate governance more vigorously, it is worried as it can be a detrimental to the company and investors. How to avoid government intervention in various aspects is a good question. This crisis will have a lasting impact. Thinking over before make decision, is the senior management needs to understand.

The existing practices are the third challenge. "Failure by the boards of direction to understand the risks their firm is taking"[8], they fall into the temptation of short-term interests. Some boards allowing or taking part in transactions that benefited their few but sacrifice the expense of the numerous, contained the benefit of their corporate.The internal controls are just a joke. They are weak or even non-existent. Problems with internal and external audit, the reason is negligent or incompetence, alternatively, the inappropriate behaviour likes aiding and abetting fraudulent. "And perhaps most importantly, a corporate culture which fosters unethical behaviour and in particular discourages difficult questions from being asked"[8]. These connected with some key drivers, like business ethics, accounting and auditing systems, principles and practices.

"Business ethics and therefore business morality generally result from an individual's own moral standards in the context of the political and cultural environment in which the organization is operating."[10] At the individual level, unethical acting is the cause of chaos in boards. It will lead to mistrust of big business, and the benefit of company falls victim. The corporation looks like a very loosely structured organization. It is very easy to defeat from outside. Feeling the threaten, rethinking the problem of business ethics, finding a solution to this problem, and then the corporate governance will be transformed. 
Accounting and auditing is a crucial thing in governance. It helps to ensure whether the firms are run efficiently, whether the public records kept accurately, and whether the taxes paid properly. [11] The chaotic auditing will lead to a disaster, it provides the chance for corruption. To reduce the risk and to enhance the perceived integrity of financial reports, trying new approaches in supervision and control could be paid attention to. But the monitoring costs could be very expensive, how to get the most accurate information of itself while keep its benefit, should be carefully considered. By the way, because of the globalization, " The International Accounting Standards Committee (IASC) and the International Auditing Practices Committee (IPAC) have close links with IOSCO and are further forces working towards global harmonization and standardization of financial reporting and auditing standards. "[3] It is also leading towards convergence.

The forth is the attitude towards reform. Some evidence shows that, some boards believe good corporate governance may put the company at a competitive disadvantage because they have no trust in legal, judicial and regulatory.Sufficient incentives and disciplines may let the competitors find out more information."All lay load on the willing horse. "Another attitude is "lazy". They are satisfied with the condition they have and enjoy it, any change is useless. No real pressure pushes they change. What they need to do is simply being 'along for the ride'.[8].Perhaps "commitment and leadership driving change in political, regulatory, and board and executive levels"is needed. So it is also extremely important to strengthen qualifications of directors, developing leadership role of the chairman, and realizing the corporate social responsibility of their own.They are all drivers.

Directors are the brain of a company. If directors are lack of foresight and do not think about the interests of the overall situation, choosing the wrong person for the job and doing investment in the wrong area could be very easy.This will cause the corporate collapse in danger. Specialized knowledge or necessary experience should be required, so is the good presentation and communication skill, and demonstrated leadership skills, project management, ability to manage multiple priorities. An ability of Crisis PR needs to be focussed on. At the same time, the directors should realize the power they have also meant the responsibility on the shoulders. Only in this way the reform of governance could be successful [12].

If the corporation merely sees the benefit of itself, it will not care others, like the business market, and the public, then the rights and interests of others will be injured. It is a vicious cycle because when harm happened, the public will lose the trust and the confident of the corporation. At last the company may precipitate a crisis. Corporate governance has to learn what the society needed and change the governance to fit it. Then the public base can be gotten.

The fifth is "impediments from a particular sector", such as the state-owned enterprise.They are under performing in many countries, just because the poor corporate governance.They have troubles in conflicting objectives, political interference, conflicting roles of government itself[8].

\section{CONCLUSION}

As discussed upon, thanks to the scandals, power abuse and the economic crisis, corporate governance has received increased attention from public, the topic is becoming popular and growing corporations have already realized the importance to be well corporate governance company. A well-defined corporate governance provides a theory that they protect the benefit of everyone concerned together with gaining profit. They also give respect to the ethical standards and the law. The forces for convergence of corporate governance are very strong now. There are all kinds of key drivers of the future direction of corporate governance principles, policies and practices. Challenges are waiting for all the company, government and market[3]. It seems a long way to go.

\section{REFERENCES}

[1] A. Cadbury, Report of the Committee on the Financial Aspects of Corporate Governance, Gee, London, December, 1992

[2] Asian Development Bank, Institute of professional studies corporate governance, 2003, [online] Available from: http://zh.scribd.com/doc/81965138/Corporate-Gov-Principles

[3] B.Tricker,The Cultural Dependence of Corporate Governance, Corporate Governance.2011, [Blog] Available from : http://corporategovernanceoup.wordpress.com/

[4] B.O'Connell, Models of Corporate Governance, 2011, [online] Available from :

http://www.ehow.com/list_6710522_models-corporate-governance.ht $\mathrm{ml}$

[5] A.Greenspan, Remarks at the Wharton School, University of Pennsylvania, Philadelphia, Pennsylvania,The federal reserve board, 2005, [online]

Available

from: http://www.federalreserve.gov/boarddocs/speeches/2005/20050515/d efault.htm

[6] G.Farrell,Sarbanes-Oxley law has been a pretty clean sweep, USA Today, 30 July, 2007.[online] Available from :

http://www.usatoday.com/money/companies/regulation/2007-07-29-s arbanes-oxley_N.htm

[7] P.Bolton, China: A New Model of. Corporate Governance?, Corporate Governance Taskforce Co-Chair. June 1 2005. [online] Available from:

http://policydialogue.org/files/events/Bolton_Presentation_New_mod el.pdf

[8] M.Webb,"Corporate governance - challenges, opportunities andreturns", The qatar corporate governance conference, Doha, 13 14 September 2006

[9] ERM and B.Taylor, Effects of Economic Crisis on Corporate Governance, Erm Initiative Faculty, 2009 [online] Available from: http://poole.ncsu.edu/erm/index.php/articles/entry/economic-crisis-go vernance/

[10] Applied-corporate-governance, Define Business Ethics - Discussion and Debate, 2009, [online] Available from :http://www.applied-corporate-governance.com/define-businessethics.html

[11] Occupational Outlook Handbook,Bureau of Labor Statistic, 2009, [online] Available from: http://www.bls.gov/oco/oco2001.htm\#nature

[12] Erawan, Qualification of Directors,n.d., [online] Available from: http://erawan.listedcompany.com/misc/Qualification\%20of\%20Direct ors.pdf

[13] N.McGregor, guide to FN1105A InternationalBusiness Finance, University of Abertay Dundee, unpublished, 2011 